\title{
Transport Phenomena in a Crystal Induced by the Energy Pulse
}

\author{
A. E. Pogorelov \\ G.V.Kurdyumov Institute for Metal Physics, N.A.S. of Ukraine, \\ 36 Academician Vernadsky Blvd., \\ UA-03680 Kyyiv-142, Ukraine
}

The phenomenon of rapid mass-transfer in solid state observed in metals after pulsed action is characterized by transfer of atoms within the short periods of action time to the depths significantly exceeding the diffusion depth under the conditions of stationary annealing. The features of other transport phenomena (mass-transfer, heat-transfer, etc.) arising in metal at pulsed energy action on a crystal are also discussed. The best instrument to study transformations in the matter under pulsed action is an easily controlled laser pulse. In a given work, the nature and correlations between transport phenomena in metals excited by the energy pulse are studied.

Швидкісна деформація металів у твердій фазі призводить до генерації і перенесення дефектів кристалічної гратниці на значні віддалі. В таких умовах атоми проникають на глибини, які істотно перевищують глибину дифузії в умовах стаціонарного відпалу за такі ж самі терміни часу. Прискорене перенесення атомів може також супроводжуватися й іншими явищами перенесення (електро- і теплоперенесення) в металі за умов дії енергетичного імпульсу на кристал. Найкращим джерелом такого імпульсу є легкокероване лазерне опромінення. В даній роботі встановлено природу та взаємозв'язок між транспортними явищами в металах, збуджених енергетичним імпульсом.

Скоростная деформация металлов в твёрдой фазе приводит к генерации и переносу дефектов кристаллической решётки на значительные расстояния. В этих условиях атомы проникают на глубины, существенно превышающие глубину диффузии в условиях стационарного отжига за сопоставимые времена. Ускоренный перенос атомов может также сопровождаться и другими явлениями переноса (электро- и теплоперенос) в металле при воздействии энергетического импульса на кристалл. Наилучшим источником такого импульса является легкоуправляемое лазерное излучение. В данной работе установлены природа и взаимосвязь между транспортными явлениями в металлах, возбуждённых энергетическим импульсом. 
Key words: mass transfer, heat transfer, laser pulse irradiation.

(Received 14 June, 2013)

\section{INTRODUCTION}

High-speed deformation of metals in a solid phase leads to generation and transport of the crystal lattice defects to the significant distances. As shown in [1], dislocations are the most probable mass carriers. Their formation at the laser pulse action has been confirmed experimentally in $[2,3]$. Direct studies of the concentration changes with the application of radioactive isotopes have shown that the region of increased content of dislocations $(30-40 \mu \mathrm{m})$ is several times larger than the region of mass-transfer [4]. At the same time, the mass-transfer proceeds to the depths, which exceed the region of a laser pulse thermal influence several times.

It is assumed [5] that dislocations, moving under the influence of stresses $\sigma$, spreading deep into the crystal away from the deformation pulse $P_{i}$ excited region, capture point defects and carry them away deep into the crystal. The point defects, captured by a dislocation, are carried into a crystal to the depth determined by the binding energy of a defect with a dislocation and its velocity $V$. Based on this, the authors of [6] were not only observing the mass-transfer, but were also registering the appearance of the electrical potential at the opposite sides of the pulse-squeezed metal sample, and in [7] — the acceleration of the heat transfer. In a given paper, we study the nature and correlation between the transport phenomena in pulse-deformable metals.

\section{EXPERIMENT}

Transport processes taking place in a crystal have a threshold nature and are determined by the criterion, which sets the boundary between stationary and highly non-stationary states of matter [8]. This boundary is determined by comparing the time $t_{i}$ of injection of the energy portion into the substance and its relaxation time $t_{r}$. In the case when $t_{i} \geq t_{r}$, the relaxation processes occur in a stationary or quasi-stationary mode. If $t_{i}<$ or $<<t_{r}$, the mode turns from the quasi-stationary to a highly non-stationary.

For generation of dislocations in a crystal, it is required that the portion of injected energy is sufficient to induce stresses $\sigma>E$ (Young's module), and for the motion of dislocations $\sigma>\left(10^{-4}\right.$ $\left.10^{-2}\right) E \approx \sigma_{P}$ (Peierls stresses). When selecting a mode, it is also important to remember that considerable portions of energy may result in the crystal destruction. In this connection, it is necessary that the temperature of the surface $T_{S} \leq T_{L}$-temperature of thermal destruc- 
tion of the crystal.

When irradiating the region $d$ with an axisymmetric laser beam, the required criterion is determined in the first approximation as

$$
t_{c}=\pi d^{2} /(4 k)
$$

where $k$ is the thermal diffusivity of material. As follows from (1), the critical time $t_{c}$ of the energy injection strongly depends on the size of the irradiated area $\sim d^{2}$. When irradiating metals by laser pulses in the free generation mode $\left(\tau_{i} \approx 10^{-3} \mathrm{~s}\right)$ or by continuous radiation, the relaxation is restricted only by thermal conductivity mechanism. The magnitude of the arising temperature gradient does not cause the essential strains, which would lead to the formation of excess number of structural defects such as dislocations and interstitial atoms.

When irradiating metals by giant laser pulses with $\tau_{i} \approx 10^{-8} \mathrm{~s}$, the energy relaxation cannot be only provided by thermal conductivity mechanism. This process causes very high temperature gradient accompanied by abrupt thermal expansion of irradiated area and appearance of thermal stresses $\sigma$.

The relaxation of excess energy is additionally realized through the appearance of a shock wave in a metal and generation of excess amount of structural defects of all types, including point and linear ones. As a result, taking into account the number $n$ of laser actions, the density of dislocations $\rho$ on depth $z$ is determined from [5]:

$$
\rho_{i}(z, t)=\rho_{i-1}-\frac{2 \alpha}{(1-v)|\mathbf{b}|} \int_{1}^{n} \nabla T(0, z, \lambda \tau) d \lambda,
$$

where $\alpha$ is the coefficient of metal thermal expansion, $\lambda$ is the variable of integration, $\nabla T$ is the temperature gradient, $\tau$ is the time of laser action, $i$ is the number of laser action, $\mathbf{b}$ is the Burgers vector, and $v$ is the Poisson coefficient.

\section{RESULTS, ANALYSIS AND DISCUSSION}

Distribution of the dislocation density after the pulsed laser action obtained in [5] using Eq. (2) (continuous curve, $i=10$ ) and electron microscopy studies [2] (points), is presented in Fig. 1.

Figure 1, $a$ shows that transfer of atoms occurs within the boundaries of the area with the increased dislocation density. Dislocations, being carried away from the laser-excited surface by the strain field $\sigma$, capture point defects and transfer them to the depth (Fig. 1, b). Flows of mass or heat $Q$, described correspondingly by Fick and Fourier equations, in the case of presence of external driving force $F$ can be written as 

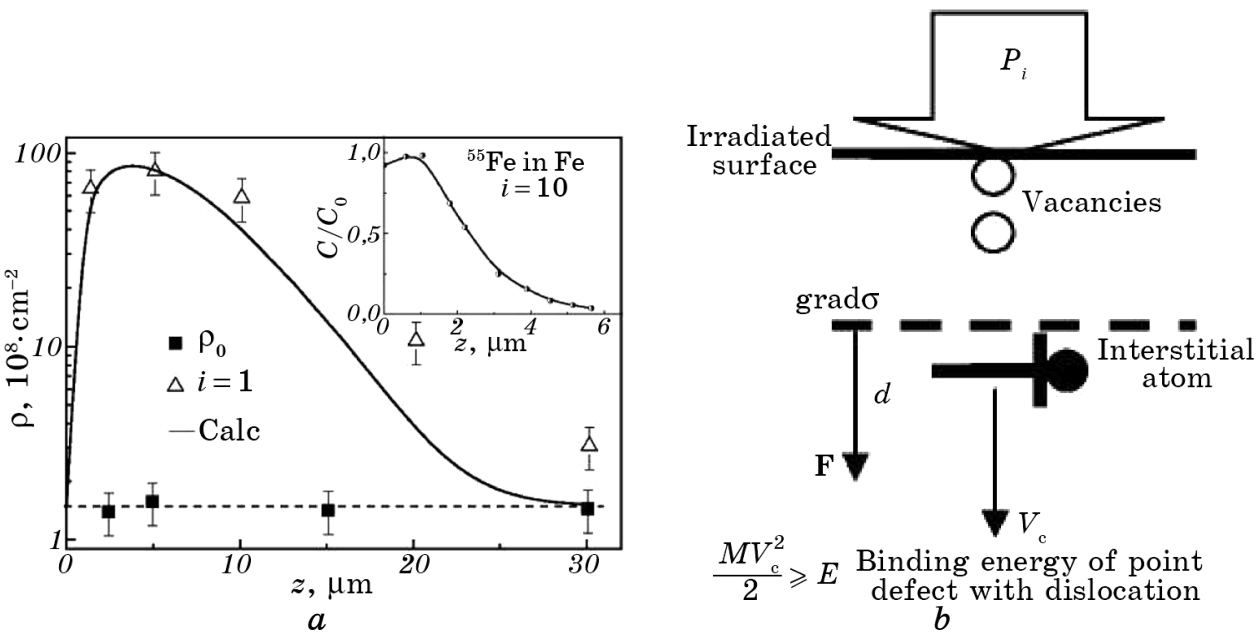

Fig. 1. Generation of dislocations $(a)$ and a scheme of mass-transfer $(b)$ in pulse-deformable metal induced by them. Inset in $(a)$ shows the concentration of ${ }^{55} \mathrm{Fe}$ in $\mathrm{Fe}$ after 10 laser actions; $\mathbf{F}$ is a vector of external driving force determined by a moving stress gradient.

$$
Q=-K(d M / d z)+M<v>_{F},
$$

where $K$ is the coefficient of proportionality characterizing certain physical process, $M$ is a physical quantity transferred in the direction of $z$ (with the average velocity $\langle v>$ in the presence of driving force $F$ ): in the case of mass transfer, this quantity is the concentration $C$, and in the case of heat transfer, it is the temperature $T$. Thus, the 'acceleration' of heat transfer should be expected during the pulse action along with the accelerated mass transfer.

This hypothesis is tested using the laser-flash method, described in [9]. We perform a thermal sensing of the pair of similar flat disk-shape samples of identical thickness $(1 \mathrm{~mm})$ made of preliminary annealed pure Fe. The irradiation was carried out in two, according to (1), critical modes-quasi-stationary with $\tau_{1} \approx 10^{-3} \mathrm{~s}$ and highly non-stationary with $\tau_{1} \approx 10^{-8} \mathrm{~s}$, at which the effect of mass-transfer acceleration in a solid phase was observed. After that, we compare the time of the temperature rise to the half of its maximum $T_{m} / 2$ on the side of the sample opposite to laser irradiated one, using the differentially connected thermocouple. Thermocouple signal was recorded using high-sensitivity and high-speed ADC and was also controlled with the storage oscilloscope. It was found that $d T /\left.d t\right|_{\tau 1}<d T /\left.d t\right|_{\tau 2}$ when the matter is in a highly non-stationary mode, $t_{1 / 2}$ is approximately $10^{-6} \mathrm{~s}$, i.e. smaller than that in the case of irradiation in a quasi-stationary mode.

Considering the similarity of the approach in description of the 
mass- and heat-transfer expressed by Eq. (3), and also the nature of the heat-transfer in metals, the observed phenomena can be described as follows. Thermal conductivity in metals is realized by both phonons and, preferentially, conduction electrons, which in real metals are getting scattered on structural defects, in particular, dislocations [10]. Thermal conductivity $K$ is inversely proportional to the thermal resistance $W_{d}$ related to the scattering of phonons on dislocations and following $[10,11]$ can be presented as

$$
K^{-1}=W_{d} \sim \delta l \sin \varphi,
$$

where $l$ is the dislocation length, $\delta$ is the dislocation scattering cross section, and $\varphi$ is an angle between the axis of a dislocation and the direction of thermal gradient propagation.

Thus, as follows from (4), there are several ways to reduce $W_{d}$. Thermal resistance of the crystal is maximal when the dislocation line is perpendicular to the thermal flow. Scattering of the phonons on dislocations will decrease both with the reduction of $\varphi$ [11] and with the reduction of time of the phonons' interaction with the dislocation that is proportional to $\delta$.

It follows from the discussion above that when moving in one direction with the dislocations, phonons would either not be scattered on synchronously moving dislocations, or will gain an additional impulse in the direction of motion. Thus, in the case of collective and directed motion of dislocations, playing role of scattering centres for phonons and conduction electrons, the effective thermal resistance in this direction will decrease. In our case, it is manifested by the registered increase of the thermal diffusivity in the direction of a probing thermal pulse.

Taking the mean free path of the particles scattered by dislocations proportional to $\rho^{-1 / 2}$, we find out that time required for the thermal pulse to pass through the crystal with $\rho=10^{8} \mathrm{~cm}^{-2}$ and with $\rho=10^{10} \mathrm{~cm}^{-2}$ will differ by 10 times. These estimations are valid for the thermal probing of samples with the constant value of $\rho_{i}$ in each case and may be useful for comparative assessment of the degree of sample deformation. In our case, the thermal pulse was passing through the sample simultaneously with the generation of the mobile dislocations.

It can be concluded that at highly non-stationary conditions, caused by pulsed action, the decrease of scattering of the particles responsible for thermal-transfer should result in a noticeable increase of the electric conductivity $\varepsilon$ of the metal. It is related to the possibility that under such conditions there will be an effect of entrainment of conduction electrons by phonons $[12,13]$. This phenomenon is supported by the appearance of the electric potential at pulsed mechanical action on the metal [6]. It does not contradict with the Wiedemann-Franz law 


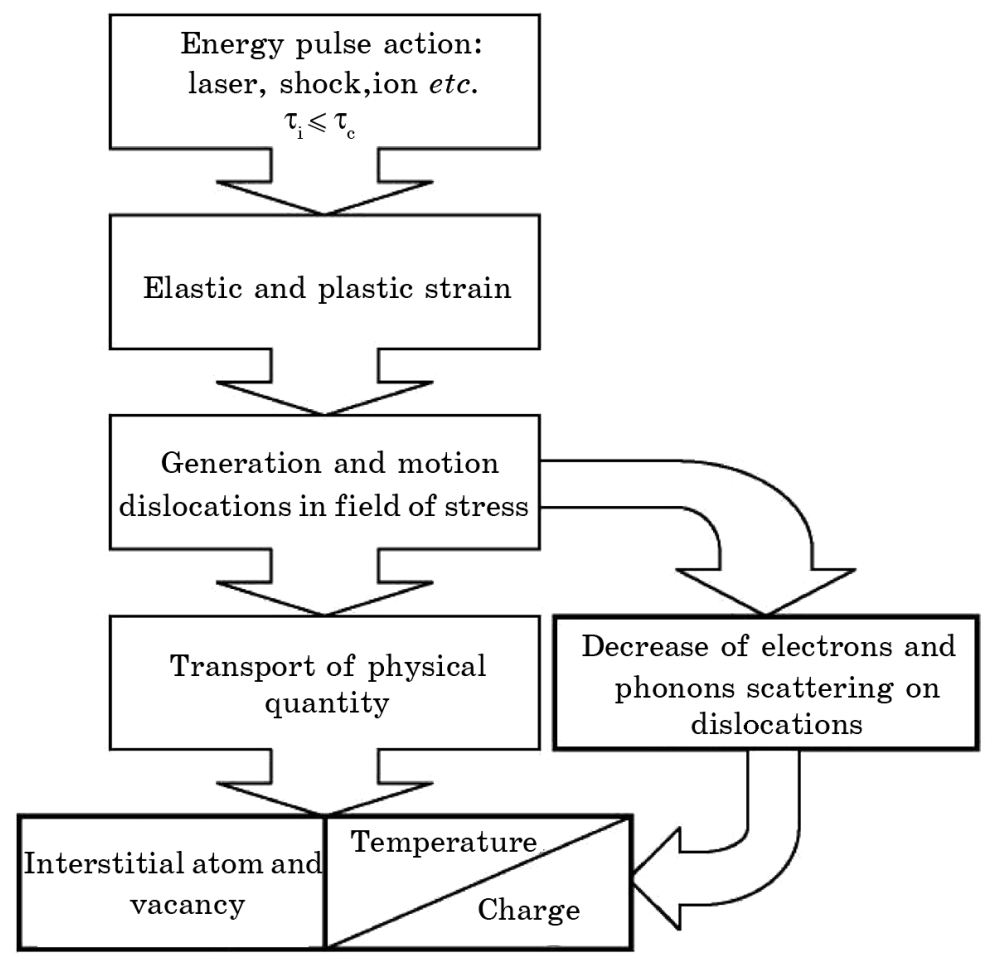

Fig. 2. Flow chart showing the links between the transport phenomena induced in a crystal by the energy pulse.

that establishes the relation between thermal conductivity $K$ of metal and its electric conductivity $\varepsilon$. Thus, the transport phenomena induced in the crystal by the energy pulse may be represented by the flow chart shown in Fig. 2.

\section{CONCLUSIONS}

We discuss the peculiarities of some transport phenomena (masstransfer, heat-transfer, etc.) arising in metal at pulsed energy action on a crystal. As shown, the connection between these phenomena is based on interaction of electrons and phonons with dislocations generated in a crystal. Dislocations with entrapped point defects are moving in the stress fields caused by the pulsed action and are directed away from an excited surface deep into crystal. The correlation between the transport processes is supported by experimental results showing the accelerated transport of both marked atoms and thermal pulse, and by the appearance of the electric potential. Studies of thermal characteristics were performed using laser-flash method in two modes deter- 
mined by the criterion for the appearance of the non-stationary conditions at the pulse action. The established correlation between the time of heat-transfer and dislocation density in a crystal may be used for the comparison of the degree of sample deformation. Taking into account the electronic character of thermal conductivity in metals, we propose a general character of heat- and electro-transport to pulse-deformable crystals. The generality of the nature of observed transport phenomena is in a good agreement with known physical laws.

\section{REFERENCES}

1. A. Pogorelov and A. Zhuravlev, Defect and Diffusion Forum, 194-199: 1247 (2001).

2. P. Yu. Volosevich and A. E. Pogorelov, Poverhnost' (Fizika, Khimiya, Mekhanika), 9: 126 (1986) (in Russian).

3. L. N. Larikov, E. A. Maksimenko, and A. E. Pogorelov, Metallofiz. Noveishie Tekhnol., 7, No. 2: 116 (1985) (in Russian).

4. A. E. Pogorelov, Napravlennyj Massoperenos v Fe i Al pri Impul'snom Lazernom Obluchenii (Thesis of Disser. for PhD) (Kiev: Institute for Metal Physics, Ukr.A.S.: 1985) (in Russian).

5. A. E. Pogorelov, K. P. Ryaboshapka, and A. F. Zhuravlev, J. Appl. Phys., 92: 5766 (2002).

6. V. P. Bevz, V. F. Mazanko, A. V. Filatov, and S. P. Vorona, Metallofiz. Noveishie Tekhnol., 28: 271 (2006) (in Russian).

7. A. E. Pogorelov, Proc. of the 1-st International Conference on Nanomaterials: Applications and Properties NAP-2011 (September 27-30, 2011), vol. 2, p. 414.

8. A. Pogorelov, Proc. of International Conference NANO-2010 (October 19-22, 2010) (Kyiv: 2010), p. 162.

9. M. E. Gurevich and A. E. Pogorelov, Fizicheskie Metody Issledovania Metallov (Physical Methods of Metals Investigation) (Kiev: Naukova Dumka: 1981) (in Russian).

10. V.S. Oskotskii and I. A. Smirnov, Defekty $v$ Kristallakh i Teploprovodnost' (Defects in Crystals and Heat Transfer) (Leningrad: Nauka: 1972) (in Russian).

11. N. V. Lugueva, S. M. Luguev, and A. A. Dunaev, Phys. Solid State, 45: 449 (2003).

12. L. Gurevich, J. Phys., 9: 477 (1945); ibid., 10: 67 (1946).

13. J. Bardeen and D. Pines, Phys. Rev., 99: 1140 (1955). 